\title{
Association of gastric epithelial apoptosis with the ability of Helicobacter pylori to induce a neutrophil oxidative burst
}

\author{
I. MIZUKI, T. SHIMOYAMA, S. FUKUDA, Q. LIU*, S. NAKAJI* and A. MUNAKATA \\ First Department of Internal Medicine and * Department of Hygiene, Hirosaki University School of Medicine, 5 \\ Zaifu-cho, Hirosaki 036-8562, Japan
}

\begin{abstract}
Both polymorphonuclear cell infiltration and increased epithelial apoptosis are seen in gastric mucosa in the presence of Helicobacter pylori infection. This study examined the association between bacterial ability to stimulate an oxidative burst in neutrophils and epithelial apoptosis. Biopsy specimens were obtained from 15 patients to detect apoptotic cells by the TUNEL method. $H$. pylori strains isolated from corresponding stomach biopsy samples were tested for the ability to stimulate an oxidative burst in human neutrophils. Neutrophils were isolated from healthy subjects without $H$. pylori infection and the oxidative burst was measured by flow cytometry with dichlorofluorescein diacetate. Stimulation with $\boldsymbol{H}$. pylori increased both the percentage of activated cells and fluorescence intensity. There was a significant positive correlation between the number of epithelial apoptotic cells and fluorescence intensity. Increased neutrophil oxidative burst stimulated by $H$. pylori may play a role in enhanced gastric mucosal DNA damage and consequent atrophic gastritis and gastric cancer.
\end{abstract}

\section{Introduction}

Helicobacter pylori infection is associated with the development of atrophic gastritis and gastric carcinogenesis $[1,2]$. H. pylori infection induces an acute gastritis which is followed by a chronic gastritis, both characterised by considerable polymorphonuclear leucocyte (PMNL) infiltration. The pathogenic role of reactive oxygen species (ROS) produced by PMNLs has been implicated in $H$. pylori-related gastritis. $H$. pylori activates neutrophil oxidative metabolism $[3,4]$ and increased oxidative DNA damage is observed in gastric mucosa in the presence of $H$. pylori infection [5]. High levels of DNA damage can lead to cell death, and increased apoptosis is seen in gastric mucosa infected with $H$. pylori $[6,7]$. This mechanism could play an important role in the development of atrophic gastritis and gastric carcinogenesis in $H$. pylori-related chronic gastritis. On the other hand, certain H. pylori strains activate human neutrophils without opsonins [4]. Infection by $H$. pylori strains that are capable of

Received 26 July 1999; revised version received 20 Oct. 1999; accepted 22 Oct. 1999.

Corresponding author: Dr T. Shimoyama (e-mail: tsimo-hki @umin.u-tokyo.ac.jp). activating neutrophils strongly seems to induce increased oxidative DNA damage in gastric mucosa. However, the relationship between the ability of $H$. pylori to activate a neutrophil oxidative burst and DNA damage of gastric mucosa is not clear. The aim of this study was to examine the association between the inducibility of a neutrophil oxidative burst by $H$. pylori and gastric epithelial apoptosis.

\section{Materials and methods}

\section{Patients}

Patients who were diagnosed as having atrophic gastritis by upper gastrointestinal endoscopy were enrolled prospectively into the study. Patients who had received anti-ulcer agents, antibiotics and nonsteroidal anti-inflammatory drugs (NSAIDs) in the two months before the examination were excluded. All patients provided informed consent before endoscopy. Biopsy specimens obtained from the antrum were used to evaluate the grades of PMNL infiltration and bacterial density according to the updated Sydney System [8], to detect apoptotic epithelial cells by staining (see below) and to isolate H. pylori strains. Patients were eligible for the present study if mild PMNL infiltration and mild bacterial density were observed in their gastric biopsy specimen and if $H$. 
pylori was isolated from the corresponding biopsy specimen. This study was approved by the ethics committee of Hirosaki University.

\section{Bacterial culture and genotyping}

Biopsy specimens were cultured for 3-5 days on Skirrow blood agar. The bacteria were identified as $H$. pylori by colony morphology and positive oxidase, catalase and urease reactions. The clone picked strains were each suspended in $1 \mathrm{ml}$ of phosphate-buffered saline (PBS, pH 7.6).

Bacterial suspensions were centrifuged at $10000 \mathrm{~g}$ for 5 min. Bacterial DNA was extracted from the bacterial pellet with phenol-chloroform-isoamylalcohol after digestion with proteinase $\mathrm{K}$. The presence of the $\operatorname{cag} A$ gene and the allelic variation of vacA signal sequence and mid-region were determined by PCR with the primers described previously $[9,10]$. PCR products were electrophoresed in agarose $2 \%$ gel. The presence of the $\operatorname{cag} A$ gene and $v a c A$ genotype was determined when the product equivalent in size to the fragment described was found $[9,10]$.

The bacterial pellet was also resuspended in Hanks's Balanced Salts Solution (HBSS) to give an absorbance at $550 \mathrm{~nm}$ of $0.5\left(c .1 .5 \times 10^{8} \mathrm{cfu} / \mathrm{ml}\right)$ for flow cytometry.

\section{Flow cytometry}

Neutrophils were isolated from two $H$. pylori seronegative healthy volunteers (A and B) by Histopaque (Sigma) density gradient separation. Briefly, peripheral blood samples were diluted two-fold in HBSS and decanted on equal volumes of Histopaque 1077 and 1119. The samples were centrifuged at $500 \mathrm{~g}$ for $30 \mathrm{~min}$. The neutrophil fraction found at the $1077 / 1119$ interphase was harvested and washed with HBSS. Neutrophils were suspended in HBSS to the required concentration.

The intracellular production of ROS in stimulated neutrophils was quantified in individual cells with a FACScan (Becton Dickinson, Heidelberg, Germany). Briefly, $100 \mu \mathrm{l}$ of neutrophil suspension $\left(2 \times 10^{3} / \mu \mathrm{l}\right)$ were incubated with $25 \mu \mathrm{l}$ of $50 \mu \mathrm{M}$ dichlorofluorescein diacetate (DCFH-DA) at $37^{\circ} \mathrm{C}$ for $15 \mathrm{~min}$. Then $100 \mu \mathrm{l}$ of bacterial suspension and $25 \mu \mathrm{l}$ of HBSS were added and incubated at $37^{\circ} \mathrm{C}$ for $30 \mathrm{~min}$. Samples were fixed with Lyse and Fix (Immunotech, Marseille, France) and were analysed within $1 \mathrm{~h}$. Flow cyotometric analysis was performed on 10000 cells. Intracellular fluorescence was measured by the histogram analysis software of the FACScan and the mean channel number was calculated to express the fluorescence intensity.

\section{Detection of apoptotic cells}

Apoptotic cells were stained by terminal uridine deoxynucleotide neck end labelling (TUNEL) with the in-situ Apoptosis Detection Kit (Oncor, Gaithersbrug, MD, USA). Briefly, paraffin-embedded gastric mucosal specimens were cut into $4-\mu \mathrm{m}$ sections and were washed with xylene and graded concentrations of ethanol to remove paraffin. After digestion for $15 \mathrm{~min}$ with proteinase $\mathrm{K}$ (Sigma) $40 \mu \mathrm{g} / \mathrm{ml}$ and blocking of endogenous peroxidase with $\mathrm{H}_{2} \mathrm{O}_{2} 3 \%$ for $30 \mathrm{~min}$, the section was incubated with digoxigenin-dUTP at $37^{\circ} \mathrm{C}$ for $1 \mathrm{~h}$. Incorporated digoxigenin was detected with anti-digoxigenin-peroxidase-conjugated antibody (Oncor). The sections were stained in diaminobenzidine hydrochloride $0.05 \%$ solution for $5 \mathrm{~min}$ and counterstained in haematoxylin for $5 \mathrm{~s}$. The number of positive cells per 10 glands was counted in three sections and the mean number was considered to be the apoptotic index. The apoptotic index was determined by two experienced pathologists (M.T., Y.T.) without knowledge of the results of the flow cytometry.

\section{Statistical analysis}

Pearson's correlation coefficient was determined to examine the correlation between mean channel number and apoptotic index. A probability (p) value of $<0.05$ was considered significant.

\section{Results}

Fifteen H. pylori strains were obtained from 15 patients with atrophic gastritis (mean age 53.7 SD 10.1, nine male and six female). All strains were $\operatorname{cag} A$ positive and $v a c A \mathrm{~s} 1 / \mathrm{m} 1$ genotype. All strains stimulated intracellular ROS production in neutrophils from two volunteers. The mean channel number of control samples was 3.09 in volunteer A (Fig. 1) and 11.11 in volunteer B. The average mean channel number of activated neutrophils was 43.46 (SEM 3.83) and 48.32 (SEM 9.28) in volunteers A and B, respectively.

Histologically, PMNL infiltration and bacterial density were graded as mild in the gastric biopsy specimens from all the patients. Apoptotic cells were observed in 12 of 15 patients and the mean apoptotic index was 1.20 (SEM 0.27). The mean channel number of neutrophils stimulated by $H$. pylori correlated significantly with the apoptotic index in the corresponding gastric mucosa. The calculated correlation coefficient was $0.716(\mathrm{p}=0.003)$ with PMNL from volunteer A (Fig. 2a) and $0.543(\mathrm{p}=0.043)$ with PMNL from volunteer B (Fig. 2b).

\section{Discussion}

Activation of human neutrophils by $H$. pylori and substances produced by $H$. pylori has been shown in various studies. H. pylori strains capable of activating 


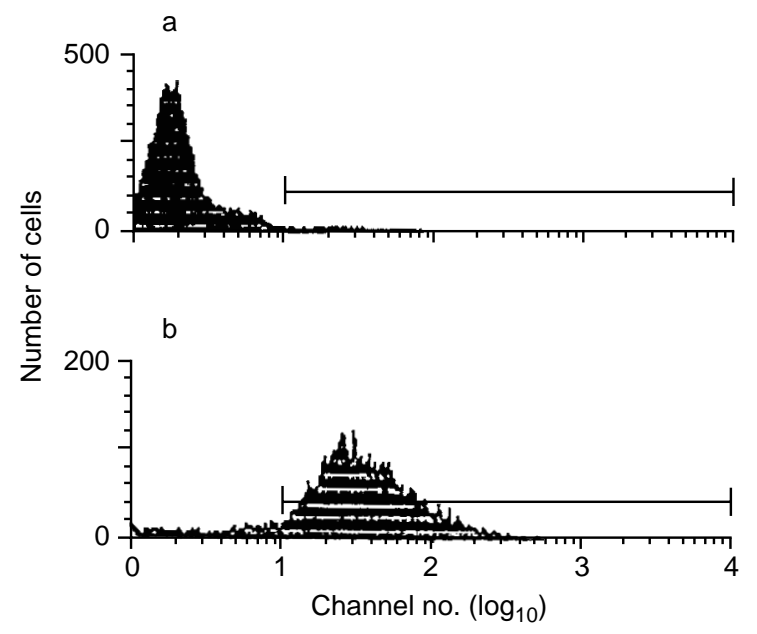

Fig. 1. Profile of fluorescence in neutrophils (a) without stimulation (control); (b) stimulated by H. pylori. Intracellular fluorescence was measured by flow cytometry and is plotted on a $\log _{10}$ scale from channel number $10^{0}$ to $10^{4}$ on the abscissa. The counts on the ordinate represent the number of cells in each channel. The region in plots represents the cells emitting fluorescence above that of unstimulated sample.

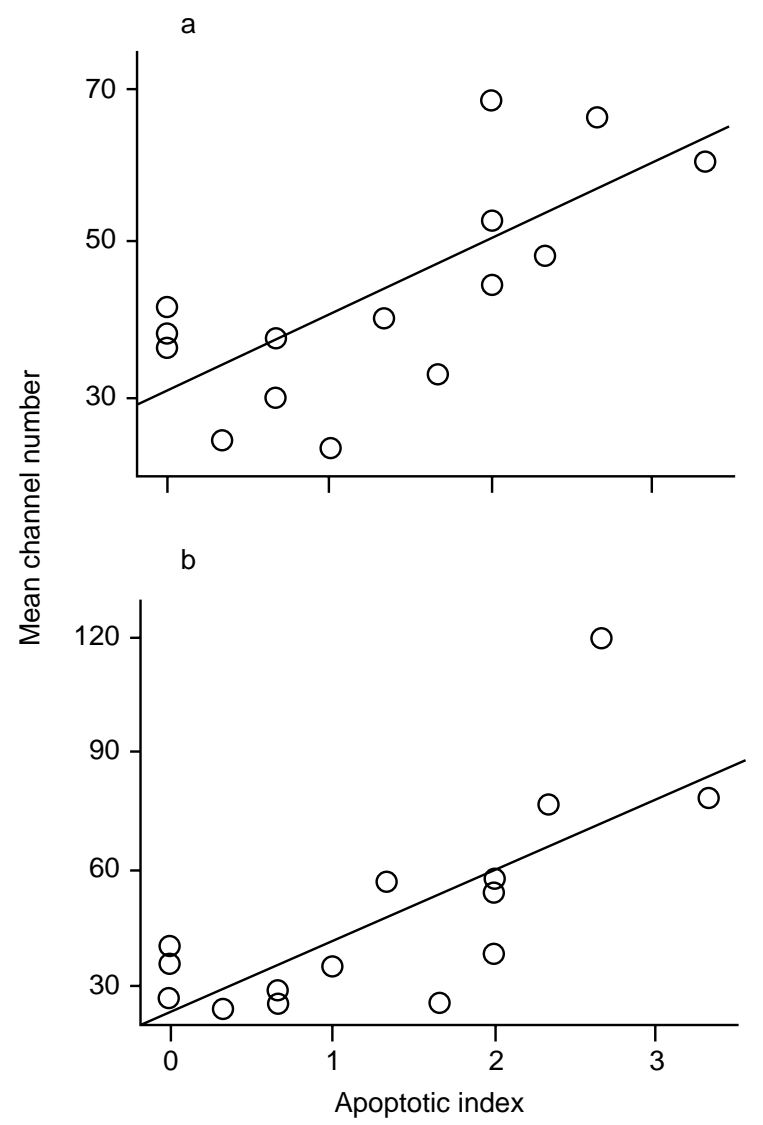

Fig. 2. Correlation between apoptotic index and mean channel number of neutrophils from (a) volunteer A; (b) volunteer $\mathrm{B}$ stimulated by corresponding $H$. pylori strains. Absuissa, apoptotic index; ordinate, mean channel number. Line represents regression line $(r=0.716$, $\mathrm{p}<0.01)$. neutrophils strongly without opsonins are associated with peptic ulcer diseases [4]. It follows that individual H. pylori strains vary in their ability to activate human neutrophils. On the other hand, increased oxidative DNA damage has been shown in gastric mucosa infected with $H$. pylori. The oxidative DNA damage is more clearly apparent in gastric mucosa with severe disease than with simple chronic gastritis [11]. If the ability of $H$. pylori strains to activate neutrophils plays a major role in oxidative DNA damage of gastric mucosa, there could be a positive correlation between them.

In the present study, the apoptotic index varied in the 15 gastric mucosa samples investigated, whereas grades of PMNL infiltration and bacterial density were similar. H. pylori strains isolated from 15 corresponding biopsy specimens were tested for the ability to activate the human neutrophil oxidative burst by flow cytometry analysis with DCFH-DA. DCFH-DA has been reported to detect the generation of intracellular $\mathrm{H}_{2} \mathrm{O}_{2}$, which is a derivative of superoxide anion, and the DCFH oxidation assay is quantitatively related to the oxidative burst of PMNLs [12]. Interestingly, the ability of $H$. pylori strains to activate the human neutrophil oxidative burst correlated significantly with the degree of epithelial apoptosis in infected gastric mucosa. The results suggested the possibility that increased neutrophil oxidative burst stimulated by $H$. pylori contributed to the high level of DNA damage and led to epithelial cell death. In an earlier study, a positive correlation was observed between the apoptotic index of gastric mucosa and the grade of glandular atrophy [13]. Furthermore, increased oxidative DNA damage is apparent in gastric mucosa with severe glandular atrophy [11]. These results suggest that infection by $H$. pylori strains capable of inducing a strong neutrophil oxidative burst may affect the degree of atrophic gastritis.

ROS are known to interact with genomic DNA and have been implicated in carcinogenesis. Increased gastric epithelial DNA damage has been observed in patients with gastric cancer, particularly in gastric cancer precursor lesions such as atrophic gastritis and incomplete intestinal metaplasia $[11,14]$. Thus, given the results of the present study, direct activation of neutrophils by $H$. pylori seems to be involved in gastric carcinogenesis. In other words, H. pylori acts as an initiator of gastric cancer.

In conclusion, the ability to stimulate the human neutrophil oxidative burst varies among $H$. pylori strains. The neutrophil oxidative burst stimulated by $H$. pylori may play a significant role in gastric mucosal DNA damage and consequent gastric epithelial apoptosis.

We are grateful to Drs K. Suzuki and T. Yoshimura for their help with flow cytometry assay and TUNEL staining, and Professor Sugawara for his excellent advice. 


\section{References}

1. Kuipers EJ, Uyterlinde AM, Peña AS et al. Long-term sequelae of Helicobacter pylori gastritis. Lancet 1995; 345: 1525-1528.

2. The EUROGAST Study Group. An international association between Helicobacter pylori infection and gastric cancer. Lancet 1993; 341: 1359-1362.

3. Mooney C, Keenan J, Munster D et al. Neutrophil activation by Helicobacter pylori. Gut 1991; 32: 853-857.

4. Rautelin H, Blomberg B, Fredlund H, Järnerot G, Danielsson D Incidence of Helicobacter pylori strains activating neutrophils in patients with peptic ulcer disease. Gut 1993; 34: 599-603.

5. Baik S-C, Youn H-S, Chung M-H et al. Increased oxidative DNA damage in Helicobacter pylori-infected human gastric mucosa. Cancer Res 1996; 56: 1279-1282.

6. Moss SF, Calam J, Agarwal B Wang S, Holt PR. Induction of gastric epithelial apoptosis by Helicobacter pylori. Gut 1996; 38: 489-501.

7. Mannick EE, Bravo LE, Zarama G et al. Inducible nitric oxide synthase, nitrotyrosine, and apoptosis in Helicobacter pylori gastritis: effect of antibiotics and antioxidants. Cancer Res 1996; 56: 3238-3243.

8. Dixon MF, Genta RM, Yardley JH, Correa P. Classification and grading of gastritis. The updated Sydney System. International Workshop on the Histopathology of Gastritis, Houston 1994. Am J Surg Pathol 1996; 20: 1161-1181.

9. Peek RM, Miller GG, Tham KT et al. Detection of Helicobacter pylori gene expression in human gastric mucosa. J Clin Microbiol 1995; 33: 28-32.

10. Atherton JC, Twells RJ, Hawkey CJ, Peek RM, Cover TL, Blaser MJ. New, internationally applicable, polymerase chain reaction-based typing of Helicobacter pylori vacA. Gut 1997; 40 Suppl 1: A1.

11. Farinati F, Cardin R, Degan P et al. Oxidative DNA damage accumulation in gastric carcinogenesis. Gut 1998; 42: $351-356$.

12. Smith JA, Weidemann MJ. Further characterization of the neutrophil oxidative burst by flow cytometry. $J$ Immunol Methods 1993; 162: 261-268.

13. Shimoyama T, Yoshimura T, Mikami T, Tanaka M, Fukuda S, Munakata A. Infection of virulent $H$. pylori strains causes different gastric epithelial cell turnover in patients with gastric cancer. Gastroenterology 1999; 116: A310.

14. Yabuki N, Sasano H, Tobita M et al. Analysis of cell damage and proliferation in Helicobacter pylori-infected human gastric mucosa from patients with gastric adenocarcinoma. Am J Pathol 1997; 151: 821-829. 